\title{
speed of remission in elderly patients with depression: electroconvulsive therapy $\checkmark$. medication
}

Harm-Pieter Spaans, Pascal Sienaert, Filip Bouckaert, Julia F. van den Berg, Esmée Verwijk, King H. Kho, Max L. Stek and Rob M. Kok

\section{Background}

Severe depression can be a life-threatening disorder, especially in elderly patients. A fast-acting treatment is crucial for this group. Electroconvulsive therapy (ECT) may work faster than medication.

\section{Aims}

To compare the speed of remission using ECT $v$. medication in elderly in-patients.

\section{Method}

The speed of remission in in-patients with a DSM-IV diagnosis of major depression (baseline MADRS score $\geqslant 20$ ) was compared between 47 participants (mean age 74.0 years, s.d. $=7.4$ ) from an ECT randomised controlled trial (RCT) and 81 participants (mean age 72.2 years, s.d. $=7.6$ ) from a medication RCT (nortriptyline $v$. venlafaxine).

\section{Results}

Mean time to remission was 3.1 weeks $(s . d .=1.1)$ for the ECT group and 4.0 weeks (s.d. $=1.0)$ for the medication group; the adjusted hazard ratio for remission within 5 weeks (ECT v. medication) was $3.4(95 \% \mathrm{Cl} 1.9-6.2)$.

\section{Conclusions}

Considering the substantially higher speed of remission, ECT deserves a more prominent position in the treatment of elderly patients with severe depression.

\section{Declaration of interest}

None.
Unipolar depression is a highly prevalent and debilitating disorder that is expected to be the second-ranked disease burden in 2020, accounting for $5.7 \%$ of all disability-adjusted life-years. ${ }^{1}$ In addition to personal suffering, depression is related to significant distress and higher morbidity in family and caregivers. ${ }^{2}$ The community prevalence of clinically relevant depressive syndromes in later life (55 and over) is $13.5 \%$, with major depression accounting for about $2 \%{ }^{3}$ In this age group depression is reported to decrease the overall quality of life and because of decreased mobility, compromised food and fluid intake, and a higher incidence of lethal suicide attempts than in younger people, depression should be considered a life-threatening disease. ${ }^{4}$ Therefore, the initial speed of response to antidepressant treatment is of major importance in these patients. Electroconvulsive therapy (ECT) is considered safe and effective in elderly people and is recommended as a preferential treatment in psychotic depression and in the case of medication resistance or intolerance. ${ }^{5-7}$ Although an older age is a positive predictor for ECT outcome, with remission rates from 73 to $90 \%$ in patients over 65 years of age, ${ }^{8,9}$ psychiatrists seem reluctant to prescribe ECT for elderly patients. ${ }^{10}$ Randomised controlled trials (RCTs) on the efficacy of ECT in elderly people are scarce and no RCT has compared ECT with medication. ${ }^{11}$ One non-randomised study on the speed of response to ECT $v$. medication for psychotic depression in elderly people showed ECT to be faster. ${ }^{12}$ To our knowledge no attempts have been made to replicate this study. Moreover, in the past decade remission has been favoured over response as an outcome parameter for improvement. ${ }^{13}$ Therefore, we aimed to compare the speed of remission after ECT $v$. medication in elderly people. Since an RCT comparing the speed of remission of ECT and medication in elderly people is particularly difficult, ${ }^{14}$ we compared elderly in-patients with severe depression from two previously published RCTs.

\section{Method}

\section{Setting and participants}

In-patients participating in an RCT comparing ECT techniques ${ }^{15}$ were compared with in-patients participating in a medication RCT. ${ }^{16}$ The ECT trial studied the efficacy and cognitive side-effects of brief pulse $v$. ultrabrief pulse unilateral stimuli over a period of 6 weeks in a group of 116 participants ( $\geqslant 18$ years). The medication trial studied the efficacy and side-effects of nortriptyline $v$. venlafaxine over 12 weeks in a group of 81 participants ( $\geqslant 60$ years). Both trials included in-patients fulfilling DSM-IV ${ }^{17}$ criteria for major depression. The severity of depression was assessed weekly in the ECT trial and in weeks 1 , $3,5,7,9$ and 12 in the medication trial using the MontgomeryÅsberg Depression Rating Scale (MADRS) ${ }^{18}$ and Hamilton Rating Scale for Depression (HRSD, 17-item version). ${ }^{19}$ The diagnosis of major depression was confirmed using the Mini-International Neuropsychiatric Interview ${ }^{20}$ in the ECT trial and the International Diagnostic Check List ${ }^{21}$ in the medication trial.

\section{Procedure}

From the ECT trial, participants aged 60 or over with unipolar depression and with a baseline MADRS score of at least 20 $(n=47)$ were selected for this study (ECT group). Exclusion criteria were age $<60$, MADRS score $<20$ or bipolar depression (Fig. 1). Of the included patients $44.7 \%(n=21)$ received brief pulse ECT and 55.3\% $(n=26)$ ultrabrief pulse ECT. From the medication trial, all participants $(n=81)$ were included (medication group). Of these patients $49.4 \%(n=40)$ were treated with venlafaxine and $50.6 \%(n=41)$ with nortriptyline. For both the ECT and the medication groups assessments were available at baseline and at weeks 1,3 and 5 . 

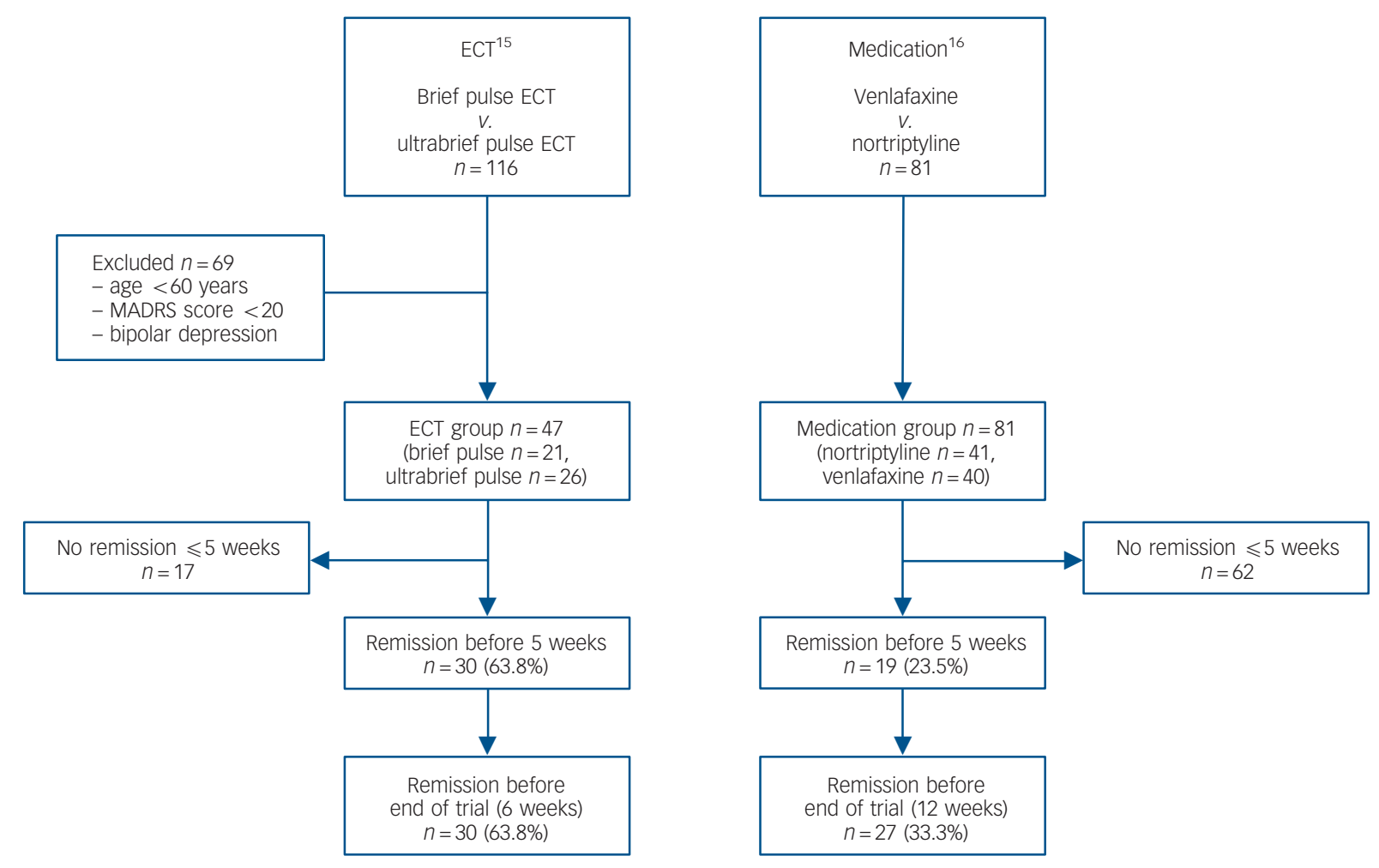

Fig. 1 Participant flow.

\section{Outcome}

The difference between the two groups in the time to achieve remission, defined as a MADRS score $<10$ within 5 weeks, was the primary outcome measure in this study. The differences in the time to achieve remission based on an HRSD remission score $\leqslant 7$ and the hazard ratios (HRs) of achieving remission within 5 weeks were defined as secondary outcome measures.

\section{Statistical analysis}

We analysed possible differences in baseline variables between the ECT group and the medication group with chi-squared tests for categorical variables and two-sided Student's $t$-tests for continuous variables, if normally distributed, or Mann-Whitney $U$-tests if not. Statistical significance was defined as $P<0.05$. Differences in mean time in which remission occurred between the ECT group and the medication group were analysed with two-sided Student's $t$-test. For a comparison between the trajectories of the ECT and medication groups we performed a Cox proportional hazards model analysis with time to remission as the outcome measure. In the first step we adjusted for age, gender, psychotic depression, severity of depression episode and late onset of first episode ( $\geqslant 55$ years) as covariates. Next, we additionally adjusted for duration of the current depression and the number of different antidepressants used to treat the current depressive episode, which could both be considered as a proxy for treatment resistance. In addition we calculated hazard ratios with $95 \%$ confidence intervals (CIs) of achieving remission with ECT compared with medication.

As we wished to compare the brief pulse and the ultrabrief pulse subgroups as a whole in the ECT group with the venlafaxine and nortriptyline subgroups taken together in the medication group, we analysed all ECT sample/medication sample comparisons with Cox's regression models to confirm whether grouping was justified. We used IBM SPSS Statistics for Windows, version 20 for all statistical analyses.

\section{Results}

The flow chart of patients is presented in Fig. 1. There were no statistical differences at baseline between the ECT and the medication group in age, gender, proportion of patients with psychotic depression, severity of depression, duration of the current depressive episode and proportion of patients with a late onset of first depression. However, the ECT group had used a greater number of different antidepressants during the current depressive episode compared with the medication group (Table 1).

The mean time to remission based on the MADRS scores was 3.07 weeks (s.d.=1.11) for the ECT group and 3.95 weeks (s.d. $=1.03 ; t(47)=-2.781, P=0.008)$ for the medication group. The mean time to remission according to the HRSD was 3.07 weeks (s.d.=1.04) for ECT and 3.50 weeks (s.d.=1.28; $t(35.8)=-1.223, P=0.229)$ for the medication group. The hazard ratio for achieving remission within 5 weeks of treatment based on the MADRS for ECT compared with medication adjusted for age, gender, percentage of psychotic depression, severity of depression and percentage late onset of first depression was 3.4 (95\% CI 1.96.2, $P \leqslant 0.001$ ) (Fig. 2). The hazard ratio after additional adjustment for the duration of the current depressive episode and the number of antidepressants to treat the current episode was 8.2 (95\% CI 3.6-19.0, $P \leqslant 0.001)$. The results for remission defined as a score of $\leqslant 7$ on the HRSD as secondary outcome were a hazard ratio of $2.7(95 \%$ CI $1.5-4.9, P=0.001)$ and $4.5(95 \%$ CI $2.0-10.2, P \leqslant 0.001)$ respectively. 


\begin{tabular}{|c|c|c|c|c|c|c|c|c|c|}
\hline & \multicolumn{2}{|c|}{ Group } & \multicolumn{2}{|c|}{ Group, total $n$} & \multicolumn{5}{|c|}{ Test statistics } \\
\hline & ECT & Medication & ECT & Medication & $t$-test (d.f.) & $\chi^{2}$ (d.f.) & $U$-test & Z & $P$ \\
\hline \multicolumn{10}{|l|}{ Demographic characteristics } \\
\hline Age, years: mean (s.d.) range & $74.0(7.4) 63-92$ & $72.2(7.6) 60-93$ & 47 & 81 & $1.328(126)$ & & & & 0.186 \\
\hline Gender, female: \% $(n)$ & $76.6(36)$ & $72.8(59)$ & 47 & 81 & & $0.219(1)$ & & & 0.640 \\
\hline \multicolumn{10}{|l|}{ Clinical characteristics } \\
\hline Psychotic, \% (n) & $53.2(25)$ & $49.4(40)$ & 47 & 81 & & $0.173(1)$ & & & 0.678 \\
\hline MADRS baseline score, mean (s.d.) range & 30.9 (6.9) 20-52 & $32.9(6.2) 22-48$ & 47 & 81 & $-1.685(126)$ & & & & 0.094 \\
\hline HRSD-17 baseline, score, mean (s.d.) range & $22.7(6.4) 8-41$ & $24.4(5.3) 13-37$ & 44 & 81 & $-1.590(123)$ & & & & 0.114 \\
\hline $\begin{array}{l}\text { Current episode duration in months, } \\
\text { mean (s.d.) range }\end{array}$ & $11.3(13.0) 1-60$ & $5.5(4.4) 1-24$ & 44 & 80 & & & 1425.500 & -1.759 & $0.079^{a}$ \\
\hline $\begin{array}{l}\text { Previous number of antidepressants } \\
\text { in current episode, mean (s.d.) range }\end{array}$ & $2.4(1.2) 0-5$ & $0.9(0.8) 0-4$ & 47 & 81 & & & 568.000 & -6.836 & $<0.001^{\mathrm{a}}$ \\
\hline Late-onset depression ( $\geqslant 55$ years), $\%(n)$ & $52.2(24)$ & $50.6(41)$ & 46 & 81 & & $0.028(1)$ & & & 0.886 \\
\hline
\end{tabular}

Using additional Cox's regression analysis, both brief pulse and ultrabrief pulse subgroups were compared with both the venlafaxine and the nortriptyline subgroups. The hazard ratio for achieving remission within 5 weeks using the MADRS were, respectively, 3.9 (95\% CI $1.7-8.7, P=0.001)$ for brief pulse ECT v. nortriptyline; 5.9 (95\% CI 2.1-16.6, $P=0.001)$ for brief pulse ECT $v$. venlafaxine; 2.3 (95\% CI 1.1-5.2, $P=0.036$ ) for ultrabrief pulse ECT $v$. nortriptyline; and 3.6 (95\% CI 1.4-9.2, $P=0.007)$ for ultrabrief pulse $v$. venlafaxine.

\section{Discussion}

\section{Main findings}

In this study, we have shown that elderly in-patients with severe depression achieved remission, as defined using the MADRS score, significantly faster if treated with ECT in comparison with antidepressants. Using the HRSD we could not confirm this finding, probably because of three missing HRSD assessments in the ECT group and one extra remission on the HRSD in the medication group. Survival analysis, with the highest sensitivity in detecting treatment group differences in speed of improvement, ${ }^{22}$

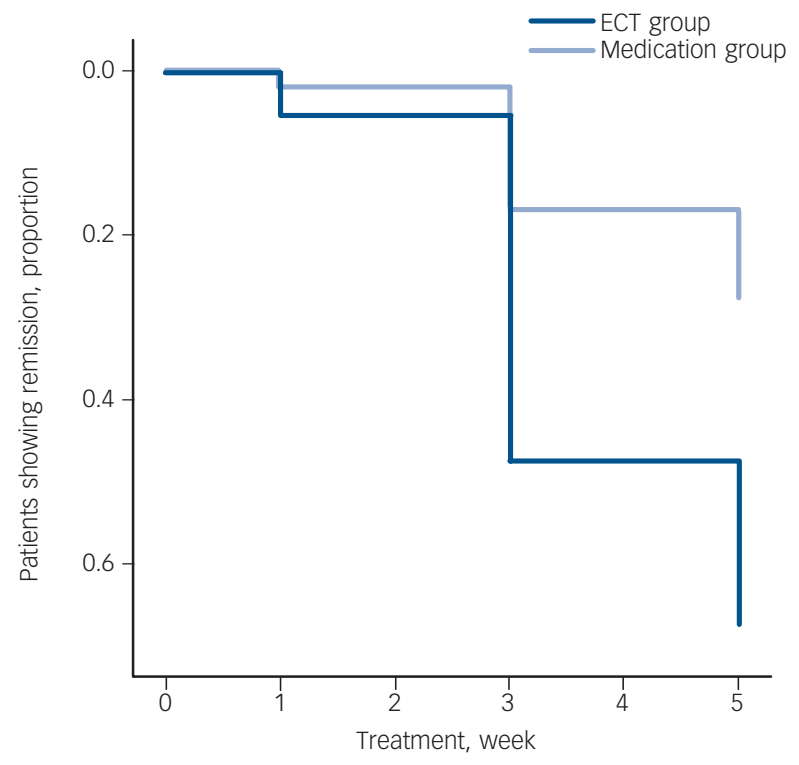

Fig. 2 Cox regression hazard ratio plot for the electroconvulsive therapy (ECT) v. medication group. favoured ECT over medication based on both MADRS and HRSD scores. Earlier remission, by nearly 1 week, could be of crucial clinical importance for an elderly patient who is severely depressed.

The differential effect of ECT using the MADRS was evident $(\mathrm{HR}=3.4)$ when adjusted for age, gender, psychotic depression, severity of depression and late-onset type as confounders. This hazard ratio could be seen as reflecting the real-life situation in many countries, where ECT will be suggested if a patient has failed at least one or two medication trials. Within 5 weeks $63.8 \%$ (30/ 47) of the patients treated with ECT remitted according to the MADRS scores, compared with only $23.5 \%$ (19/81) of the patients treated with medication. The ECT study lasted 6 weeks and no additional patients remitted between week 5 and week 6 . In the medication study, however, eight patients achieved remission between week 5 and week 12 . The final remission rates of $63.8 \%$ (30/47) after 6 weeks in the ECT group and 33.3\% (27/81) after 12 weeks in the medication group underlines the superiority of ECT even more (Fig. 1).

Although late-onset depression as well as a psychotic depression have been related to outcome, ${ }^{23,24}$ neither was significantly associated with remission in our study. The proportion with psychotic depression was substantial in both groups. Because ECT is regarded as a preferential treatment for psychotic depression, this could have introduced a bias against antidepressant monotherapy in the comparison. However, a subgroup analysis of the patients with non-psychotic depression rendered a comparable result: the hazard ratio of achieving remission within 5 weeks with ECT $(n=21) v$. medication $(n=40)$ was 3.3 (95\% CI $1.3-8.5$, $P=0.012)$ in patients with non-psychotic depression. To compensate for the reduced sample size only baseline MADRS score and duration of the current episode were included as covariates in the analysis.

\section{Findings from other studies}

We are not aware of any other study using speed of remission as an outcome criterion in elderly patients with depression. In adults only one previous RCT, that included drug naive out-patients with a male preponderance, comparing bilateral ECT (mean age 37.5 years, s.d. $=9.4) v$. imipramine (mean age 42.4 years, s.d. $=12.1$ ), analysed speed of remission and found no difference. ${ }^{25}$ One RCT that analysed completers of a unilateral stimuli ECT (mean age 47.6 , s.d. $=14.7$ ) v. paroxetine comparison (mean age 52.3, s.d. =15.7) in a sample of in-patients with treatment-resistant depression with an average of 4.9 antidepressant trials during the current episode, found the speed of response (50\% decrease 
in HRSD-21) to ECT to be superior. ${ }^{26}$ In a RCT that compared bilateral ECT (mean age 57.4, s.d.=14.1) with the addition of lithium (mean age 52.9 , s.d. $=11.5$ ) in a group of patients treated with tricyclic antidepressants, lithium addition resulted in a significantly faster decrease in HRSD score in week 1, although improvement in week 3 was not significantly different between the groups. ${ }^{27}$

Only one non-randomised study in elderly patients with psychotic depression ${ }^{12}$ has compared the speed of response in an ECT group $(n=17)$ and a medication (blood-level controlled nortriptyline combined with perphenazine) group $(n=8)$. In this study response was defined as a HRSD score $\leqslant 10$ with absence of delusions and hallucinations, a definition which approaches our definition of remission. A superior speed of response in the ECT group was found compared with the medication group. Adjusted for the duration of the current episode, the hazard ratio for response after 8 weeks was 6.71 (95\% CI 1.5-31.1) for ECT $v$. medication. Although the samples were small it is interesting that the favourable outcome of ECT in our study is in line with these results, especially when additional adjustments are made for the episode duration and number of antidepressants, with a hazard ratio of 8.2 (95\% CI 3.6-19.0).

\section{Findings from subgroup analysis}

The brief pulse subgroup of the ECT study had a faster rate of remission (3.6 v. 4.6 weeks) and higher remission rate $(68.4 \% v$. $49.0 \%)$ than the ultrabrief pulse subgroup. ${ }^{15}$ In the medication RCT no statistical difference was found between the venlafaxine and nortriptyline groups regarding the speed of remission (7.1 v. 5.8 weeks, $t(25)=1.016, P=0.319)$ and the remission rates $\left(27.5 \%\right.$ v. $\left.39.0 \%, \chi^{2}(1)=1.210, P=0.271\right) .{ }^{16}$ Although it may be debatable whether merging of both ECT subgroups is allowed because the speed of remission differed significantly in the ECT subgroups, all comparisons between ECT subgroups and medication subgroups resulted in favour of the ECT subgroups.

\section{Differences between the ECT and medication groups}

Although the ECT and medication groups had many similarities at baseline partly because of our selection criteria, some differences emerged and we have adjusted the mean outcome results for these differences. The difference in number of antidepressants used between the ECT and medication group $(2.4 v .0 .9)$ in this study fits the alleged time to complete at least one additional medication trial and is in line with the international guidelines. ${ }^{5,7}$ The difference in the mean duration of the current depressive episode (11.3 months for ECT v. 5.5 months for medication) may represent the necessary time for the extra medication trials, but may also represent extensive patient and doctor delays, in line with the reported hesitance of patients and reluctance of professionals to use ECT. ${ }^{10,14}$ Considering the evidence that with longer duration of the current depressive episode the efficacy of antidepressant treatment, $\mathrm{ECT}^{28,29}$ as well as medication, ${ }^{30,31}$ will diminish, this study suggests that the depressive burden and hospital stay may be significantly shortened by an earlier use of ECT.

\section{Strengths and limitations}

This is the first study focusing on the speed of remission and the largest study comparing ECT and medication in elderly patients with depression to date. The main limitation is that in this study results from two RCTs were used. Unknown and unsuspected confounders may not have been removed by randomisation to treatment. We were able to correct for many known important covariates but cognition, somatic and psychiatric comorbidity were assessed differently in each of the original trials and could therefore not be evaluated as potential confounders. Assessments were carried out by different groups of researchers, although both groups were trained in the use of depression ratings scales. The study assessments of the medication group were only available at baseline and in weeks 1, 3 and 5. To allow comparison between the groups at these four time points, three remissions that occurred in week 4 of the ECT study were counted in week 5, which resulted in a slight underestimation of the speed of remission with ECT.

\section{Implications}

Electroconvulsive therapy had a substantially higher speed of remission compared with antidepressants, although the patients in the ECT group had been depressed for significantly longer and had a higher degree of treatment resistance. Electroconvulsive therapy deserves a more prominent position in the treatment of elderly patients with severe unipolar depression.

Harm-Pieter Spaans, MD, Parnassia Psychiatric Institute, The Hague, The Netherlands; Pascal Sienaert, MD, PhD, Filip Bouckaert, MD, University Psychiatric Centre - Catholic University of Leuven, campus Kortenberg Kortenberg. Belgium: Julia F. van den Berg, PhD, Esmée Verwijk, MSc, King H. Kho, MD, PhD, Parnassia Psychiatric Institute, The Hague, The Netherlands; Max L. Stek, MD, PhD, VU University Medical Centre and GGZ inGeest, Amsterdam, The Netherlands; Rob M. Kok, MD, PhD, Parnassia Psychiatric Institute, The Hague, The Netherlands

Correspondence: Harm-Pieter Spaans, MD, Parnassia Psychiatric Institute, Clinical Centre for the Elderly, Mangostraat 1, 2552 KS The Hague, The Netherlands. Email: hp.spaans@parnassia.nl

First received 12 Mar 2014, final revision 7 May 2014, accepted 3 Jul 2014

\section{Acknowledgements}

All authors are members of ResPECT (Research in Psychiatry and ECT).

\section{References}

1 World Health Organization. Prevention of Mental Disorders: Effective Interventions and Policy Options: Summary Report. A Report of the World Health Organization Department of Mental Health and Substance Abuse; in collaboration with the Prevention Research Centre of the Universities of Nijmegen and Maastricht. World Health Organization, 2004.

2 Shahly V, Chatterji S, Gruber MJ, Al-Hamzawi A, Alonso J, Andrade LH, et al. Cross-national differences in the prevalence and correlates of burden among older family caregivers in the World Health Organization World Mental Health (WMH) Surveys. Psychol Med 2013; 43: 865-79.

3 Beekman AT, Copeland JR, Prince MJ. Review of community prevalence of depression in later life. Br J Psychiatry 1999; 174: 307-11.

4 Baldwin RC. Poor prognosis of depression in elderly people: causes and actions. Ann Med 2000; 32: 252-6.

5 National Collaborating Centre for Mental Health. Depression: The NICE Guideline on the Treatment and Management of Depression in Adults. British Psychological Society and Royal College of Psychiatrists, 2010.

6 Weiner RD. The Practice of Electroconvulsive Therapy: Recommendations for Treatment, Training, and Privileging (A Task Force Report of the American Psychiatric Association). American Psychiatric Association, 2001.

7 Van den Broek WW, Birkenhäger TK, de Boer D, Burggraaf JP, van Gemert B, Groenland THN, et al. Richtlijn Elektroconvulsietherapie (Guideline Electroconvulsive Therapy). de Tijdstroom, 2010.

8 O'Connor MK, Knapp R, Husain M, Rummans TA, Petrides G, Smith G, et al. The influence of age on the response of major depression to electroconvulsive therapy: a C.O.R.E. Report. Am J Geriatr Psychiatry 2001; 9: $382-90$.

9 Tew JD Jr, Mulsant BH, Haskett RF, Prudic J, Thase ME, Crowe RR, et al. Acute efficacy of ECT in the treatment of major depression in the old-old. Am J Psychiatry 1999; 156: 1865-70.

10 van der Wurff FB, Stek ML, Hoogendijk WJ, Beekman AT. Discrepancy between opinion and attitude on the practice of ECT by psychiatrists specializing in old age in the Netherlands. J ECT 2004; 20: 37-41. 
11 Stek ML, Wurff van der FB, Hoogendijk WJG, Beekman ATF. Electroconvulsive therapy for the depressed elderly. Cochrane Database Syst Rev 2009; 4: 4

12 Flint AJ, Rifat SL. The treatment of psychotic depression in later life: a comparison of pharmacotherapy and ECT. Int J Geriatr Psychiatry 1998; 13: $23-8$.

13 Thase ME. Evaluating antidepressant therapies: remission as the optimal outcome. J Clin Psychiatry 2003; 64 (suppl 13): 18-25.

14 Stek ML, van der Wurff FB, Uitdehaag BM, Beekman AT, Hoogendijk WJ. ECT in the treatment of depressed elderly: lessons from a terminated clinica trial. Int J Geriatr Psychiatry 2007; 22: 1052-4.

15 Spaans HP, Verwijk E, Comijs HC, Kok RM, Sienaert P, Bouckaert F, et al. Efficacy and cognitive side effects after brief pulse and ultrabrief pulse right unilateral electroconvulsive therapy for major depression: a randomized double-blind, controlled study. J Clin Psychiatry 2013; 74: e1029-36.

16 Kok RM, Nolen WA, Heeren TJ. Venlafaxine versus nortriptyline in the treatment of elderly depressed inpatients: a randomised, double-blind, controlled trial. Int J Geriatr Psychiatry 2007; 22: 1247-54.

17 American Psychiatric Association. Diagnostic and Statistical Manual of Mental Disorder (4th edn) (DSM-IV). APA, 1994.

18 Montgomery SA, Åsberg M. A new depression scale designed to be sensitive to change. Br J Psychiatry 1979; 134: 382-9.

19 Hamilton $M$. Development of a rating scale for primary depressive illness. Br J Soc Clin Psychol 1967; 6: 278-96.

20 Sheehan DV, Lecrubier $Y$, Sheehan $\mathrm{KH}$, Amorim $\mathrm{P}$, Janavs J, Weiller $\mathrm{E}$, et al. The Mini-International Neuropsychiatric Interview (M.I.N.I.): the development and validation of a structured diagnostic psychiatric interview for DSM-IV and ICD-10. J Clin Psychiatry 1998; 59 (suppl 20): 22-33; quiz 34-57.

21 Hiller W, Zaudig M, Mombour W. Development of diagnostic checklists for use in routine clinical care. A guideline designed to assess DSM-III-R diagnoses. Arch Gen Psychiatry 1990; 47: 782-4.
22 Nobler MS, Sackeim HA, Moeller JR, Prudic J, Petkova E, Waternaux C. Quantifying the speed of symptomatic improvement with electroconvulsive therapy: comparison of alternative statistical methods. Convuls Ther 1997: 13: 208-21.

23 Oudega ML, van Exel E, Wattjes MP, Comijs HC, Scheltens P, Barkhof F, et al. White matter hyperintensities, medial temporal lobe atrophy, cortical atrophy, and response to electroconvulsive therapy in severely depressed elderly patients. J Clin Psychiatry 2011; 72: 104-12.

24 Nordenskjold A, von Knorring L, Engstrom I. Predictors of the short-term responder rate of electroconvulsive therapy in depressive disorders a population based study. BMC PSychiatry 2012; 12: 115.

25 Selvan CP, Mayur PM, Gangadhar BN, Janakiramaiah N, Subbakrishna DK, Murali N. Comparison of therapeutic efficacy of ECT and imipramine: a randomized controlled trial. Indian J Psychiatry 1999; 41: 228-35.

26 Folkerts HW, Michael N, Tolle R, Schonauer K, Mucke S, Schulze-Monking H. Electroconvulsive therapy vs. paroxetine in treatment-resistant depression - a randomized study. Acta Psychiatr Scand 1997; 96: 334-42.

27 Dinan TG, Barry S. A comparison of electroconvulsive therapy with a combined lithium and tricyclic combination among depressed tricyclic nonresponders. Acta Psychiatr Scand 1989; 80: 97-100.

28 Dombrovski AY, Mulsant BH, Haskett RF, Prudic J, Begley AE, Sackeim HA Predictors of remission after electroconvulsive therapy in unipolar major depression. J Clin Psychiatry 2005; 66: 1043-9.

$29 \mathrm{Kho} \mathrm{KH}$, Zwinderman AH, Blansjaar BA. Predictors for the efficacy of electroconvulsive therapy: chart review of a naturalistic study. J Clin Psychiatry 2005; 66: 894-9.

30 Joel I, Begley AE, Mulsant BH, Lenze EJ, Mazumdar S, Dew MA, et al. Dynamic prediction of treatment response in late-life depression. Am J Geriatr Psychiatry 2014; 22: 167-76.

31 Kok RM, Nolen WA, Heeren TJ. Outcome of late-life depression after 3 years of sequential treatment. Acta Psychiatr Scand 2009; 119: 274-81. 